\section{(2) OPEN ACCESS}

\title{
Severity of oro-dental anomalies in Loeys-Dietz syndrome segregates by gene mutation
}

\author{
Priyam Jani (D) ,' Quynh C Nguyen (D) ,' Konstantinia Almpani (D) ,' \\ Cyrus Keyvanfar (D) ,' Rashmi Mishra (D) ,' Denise Liberton (D) ,' \\ Pamela Orzechowski (D) ,' Pamela A Frischmeyer-Guerrerio (D) ,' ${ }^{2}$ Olivier Duverger (D) ,' \\ Janice $S$ Lee (D) ${ }^{1}$
}

\begin{abstract}
- Additional material is published online only. To view, please visit the journal online (http://dx.doi.org/10.1136/ jmedgenet-2019-106678).

${ }^{1}$ Craniofacial Anomalies and Regeneration Section, National Institute of Dental and Craniofacial Research, Bethesda, Maryland, USA

${ }^{2}$ Food Allergy Research Unit, National Institute of Allergy and Infectious Diseases, Bethesda, Maryland, USA
\end{abstract}

\section{Correspondence to}

Dr Olivier Duverger, Craniofacial Anomalies and Regeneration Section, National Institute of Dental and Craniofacial Research, Bethesda, MD 20892, USA; olivier.duverger@nih.gov and Dr Janice $S$ Lee, Craniofacial Anomalies and Regenration Section, National Institute of Dental and Craniofacial Research, Bethesda, MD, 20892; janice.lee@nih.gov

Received 4 November 2019 Revised 17 January 2020 Accepted 28 January 2020 Published Online First 8 March 2020

Check for updates

(C) Author(s) (or their employer(s)) 2020. Re-use permitted under CC BY-NC. No commercial re-use. See rights and permissions. Published by BMJ.

To cite: Jani P, Nguyen QC Almpani K, et al. J Med Genet 2020:57:699-707.

\section{ABSTRACT}

Background Loeys-Dietz syndrome (LDS), an autosomal dominant rare connective tissue disorder, has multisystemic manifestations, characterised by vascular tortuosity, aneurysms and craniofacial manifestations. Based on the associated gene mutations along the transforming growth factor-beta (TGF- $\beta$ ) pathway, LDS is presently classified into six subtypes. Methods We present the oro-dental features of a cohort of 40 patients with LDS from five subtypes. Results The most common oro-dental manifestations were the presence of a higharched and narrow palate, and enamel defects. Other common characteristics included bifid uvula, submucous cleft palate, malocclusion, dental crowding and delayed eruption of permanent teeth. Both deciduous and permanent teeth had enamel defects in some individuals. We established a grading system to measure the severity of enamel defects, and we determined that the severity of the enamel anomalies in LDS is subtype-dependent. In specific, patients with TGF- $\beta$ receptor II mutations (LDS2) presented with the most severe enamel defects, followed by patients with TGF- $\beta$ receptor I mutations (LDS1). LDS2 patients had higher frequency of oro-dental deformities in general. Across all five subtypes, as well as within each subtype, enamel defects exhibited incomplete penetrance and variable expression, which is not associated with the location of the gene mutations. Conclusion This study describes, in detail, the oro-dental manifestations in a cohort of LDS, and we conclude that LDS2 has the most severely affected phenotype. This extensive characterisation, as well as some identified distinguishing features can significantly aid dental and medical care providers in the diagnosis and clinical management of patients with this rare connective tissue disorder.

\section{INTRODUCTION}

Genetic conditions with a prevalence of $<200000$ affected individuals within the USA are considered by the National Institutes of Health as rare diseases. ${ }^{12}$ Dental anomalies are frequently included in the phenotypic manifestations of many genetic conditions. Among 7000 known syndromes, $>900$ (13\%) exhibit dental and/or oral manifestations. ${ }^{3}$ This is likely an under-reported number as orodental anomalies and their impact on patients' quality of life are often time overlooked as they are found in combination with other, more lifethreatening, clinical manifestations.
Loeys-Dietz syndrome (LDS) is an autosomal dominant, rare connective tissue disorder with multisystemic involvement. ${ }^{4}$ LDS phenotype has been previously described as a clinical triad of hypertelorism, bifid uvula and aortic aneurysm. Other manifestations that have not been fully characterised include craniosynostosis, retrognathia, translucent skin and enamel defects. ${ }^{5}$ Mutations in the genes encoding the transforming growth factor-beta (TGF- $\beta$ ) receptor type 1 (TGFBR1) and TGF- $\beta$ receptor type 2 (TGFBR2) subunits were the first reported genetic causes of LDS; LDS1 (MIM\# 609192) and LDS2 (MIM\# 610168), respectively. ${ }^{4}$ Subsequently, mutations causing LDS were found in three additional genes, namely the mothers against decapentaplegic homolog 3, involved in the transduction of TGF- $\beta$ signalling (SMAD3, LDS3, MIM\# 613795), ${ }^{6}$ the TGF- $\beta 2$ (TGFB2, LDS4, MIM\#614816) and the TGF- $\beta 3$ (TGFB3, LDS5, MIM\#615582) ligands. ${ }^{7-10}$ More recently, mutations in the SMAD2 gene were also found to cause LDS (LDS6, no MIM\# assigned). ${ }^{11}$ Thus, LDS is caused by mutations in genes encoding various components of the TGF- $\beta$ signalling pathway: ligands, cell membrane receptors and signal transducers. Interestingly, mutations in the gene encoding the TGF- $\beta 1$ ligand (TGFB1) lead to two syndromes that are phenotypically unrelated to LDS: Camurati-Engelmann disease (MIM\# 131300) featuring skeletal dysplasia ${ }^{12}$ and a condition known as inflammatory bowel disease, immunodeficiency and encephalopathy (MIM\# 618213). ${ }^{13}$ Notably, there has been no report showing any cardiovascular, craniofacial or dental phenotype in these syndromes, which suggests that TGF- $\beta 2$ and TGF- $\beta 3$ are unique in the way they activate the pathway and impact development.

Due to the life-threatening nature of aortic aneurysm, several reports have focused on characterising the cardiovascular anomalies experienced by patients with LDS. ${ }^{14}$ Over the last decade, significant efforts have been made in improving the diagnosis and management of the cardiovascular anomalies in patients with LDS, which has helped improve the survival rate for this devastating rare disease. ${ }^{15} 16$ However, despite sporadic case reports on the oral and dental anomalies diagnosed as part of LDS, ${ }^{14-19}$ as well as numerous animal studies showing the importance of TGF- $\beta$ signalling in dental development, ${ }^{20-26}$ there has 
been no systematic report of the oro-dental phenotype in a large cohort of patients affected with this rare connective tissue disorder. The type of anomalies and the relationship between phenotype and genotype have therefore not been established for the oral and dental manifestations of this disease. Nevertheless, the impact of the dental anomalies on the oral healthrelated quality of life for patients with LDS has been recently evaluated and is significantly worse for individuals with LDS compared with their unaffected family members and the general population. ${ }^{27}$

In this study, we performed a thorough evaluation of the oral and dental anomalies in a cohort of patients with LDS from five different subtypes of the disease (LDS1-5). For the first time, we report a detailed description of the oral and dental anomalies found in these patients, establish a novel classification system for the assessment of the severity of enamel defects associated with this syndrome and determine that the severity of the dental anomalies in patients with LDS is subtype-dependent.

\section{METHODS}

\section{Study design and participants}

From August 2015 to January 2018, 40 patients with LDS, who were genetically and clinically diagnosed, were recruited and presented at the National Institutes of Health, Clinical Center Dental Clinic for craniofacial and dental evaluation. For each patient, dental evaluation and intraoral photography were obtained as part of the natural history study, and cone-beam CT when indicated per protocol. Self-reported dental health status questionnaire was also obtained (NIDCR25), including questions related to dental sensitivity, dry mouth, temporomandibular joint (TMJ) pain or discomfort, snoring and obstructive sleep apnoea. Questions related to oral health-related quality of life and access to dental care have been included in a different study. ${ }^{27}$ In addition, the results of the craniofacial evaluation and morphometrics have been prepared in a separate and complimentary study. We also included 26 unaffected family members (mean age 40.27 years, age range 6-54 years) who consented to participate in our study as healthy controls. The evaluation for family members was reduced to include an oral examination and intraoral photos for their convenience.

\section{Oral and dental evaluation}

The oral and dental evaluation included a detailed clinical examination, performed by a team of general dentists and an oral and maxillofacial surgeon. The clinicians were calibrated for clinical assessment of intraoral and extraoral features. The intraoral examination consisted of the inspection of the oral structures and soft tissue, including the palate, uvula and gingiva. The dental and hard tissue evaluation included the occlusion, eruption pattern, tooth morphology, jaw relationship and TMJ function. A standardised oro-dental evaluation form was used in all cases. Cone-beam CT (Planmeca Promax 3D Max, $400 \mu \mathrm{m}$ resolution) or available dental radiographs and intraoral photography (Canon EOS 5D Mark II camera) were performed to further assess dental phenotypes including findings such as tooth impaction, dental decay and enamel defects. For each patient, seven intraoral photos were taken: the frontal view of dentition in occlusion, the frontal view of dentition at rest (2-3 mm leeway space), the maxillary arch, the mandibular arch, the left lateral view (maxillary and mandibular teeth in occlusion), the right lateral view, and the oropharyngeal region.
Table 1 Demographics of study population

\begin{tabular}{llll}
\hline & & \multicolumn{2}{l}{ Age at first visit (years) } \\
\cline { 3 - 4 } Characteristics & No. of patients (\%) & Mean \pm SD & Range \\
\hline Total subjects & $40(100)$ & $18.05 \pm 15.0$ & $2.4-57.4$ \\
\hline $\begin{array}{l}\text { Gender } \\
\quad \text { Male }\end{array}$ & $20(50.0)$ & $17.5 \pm 16.0$ & $2.4-55.0$ \\
\hline $\begin{array}{l}\text { Female } \\
\text { Pathogenic gene mutations }\end{array}$ & $20(50.0)$ & $18.6 \pm 14.3$ & $2.4-57.4$ \\
\hline \multicolumn{1}{l}{ Loeys-Dietz syndrome (LDS) } & & & \\
\hline \multicolumn{1}{l}{ TGFBR1 (LDS1) } & $15(37.5)$ & $17.4 \pm 15.2$ & $3.7-55.0$ \\
\hline \multicolumn{1}{l}{ TGFBR2 (LDS2) } & $14(35)$ & $18.1 \pm 15.5$ & $3.2-57.4$ \\
\hline SMAD3 (LDS3) & $3(7.5)$ & $19.7 \pm 15.9$ & $3.8-35.5$ \\
\hline TGFB2 (LDS4) & $7(17.5)$ & $16.8 \pm 17.2$ & $2.4-39.8$ \\
\hline TGFB3 (LDS5) & $1(2.5)$ & $37.5 \pm n / a$ & $n / a$ \\
\hline
\end{tabular}

$\mathrm{n} / \mathrm{a}$, noted for range and SD with sample size of $1 ; S M A D 3$, signal transducer in transforming growth factor-beta; TGFB2, transforming growth factor-beta 2; TGFB3, transforming growth factor-beta 3; TGFBR1, transforming growth factor-beta receptor $1 ;$ TGFBR2, transforming growth factor-beta receptor 2 .

\section{Classification of enamel defect}

Based on the clinical presentation and severity of enamel defect, the authors formulated the dental classification as part of the effort to map the relationship between severity of enamel defect and pathogenic variants associated with LDS. The severity of enamel defects was graded using a modified version of the classification of enamel defect in coeliac disease. ${ }^{28}$ The classification of dental enamel defects was applied for both deciduous and permanent dentitions. Intraoral photos of unaffected family members were graded similarly to use as control.

\section{Data analysis}

All descriptive analyses were performed using GraphPad Prism V.8.0.2 for Windows (GraphPad Software, La Jolla, California, USA) and IBM SPSS Statistics for Windows, V.26.0 (IBM, Armonk, New York, USA). The descriptive statistics consisted of univariate analyses for all LDS subject and included mean, SD and range, unless otherwise specified. As this was a descriptive study, no formal statistical comparisons were made across phenotypic subcategories.

\section{RESULTS}

\section{Demographics}

The demographic characteristics of the cohort of patients with LDS enrolled in this study are summarised in table 1. Forty patients were enrolled in total, with an equal number of males $(n=20)$ and females $(n=20)$, with a broad age range (mean: $18.05 \pm 15.0$ years, range: $2.4-57.4$ years) . Both the primary and permanent dentitions were assessed and evaluated.

Thus far, most subjects have been reported to carry the mutation in TGFBR1 (LDS1) or TGFBR2 (LDS2) genes, while fewer cases have been reported for the other three subtypes. ${ }^{17}$ This frequency distribution was reflected in the cohort of 40 patients with LDS who were enrolled in this study: 15 subjects were LDS1 (mutation in TGFBR1), 14 subjects were LDS2 (mutation in TGFBR2), 3 subjects were LDS3 (mutation in SMAD3), 7 subjects were LDS4 (mutation in TGFB2) and only 1 subject was LDS5 (mutation in TGFB3) (table 1). No patients with LDS6 (mutation in SMAD2) were included in this study. 
Table 2 Oro-dental characteristics of LDS-causing mutations

\begin{tabular}{|c|c|c|c|c|c|c|}
\hline & $\begin{array}{l}\text { TGFBR1 } \\
\text { (LDS1) }\end{array}$ & $\begin{array}{l}\text { TGFBR2 } \\
\text { (LDS2) }\end{array}$ & $\begin{array}{l}\text { SMAD3 } \\
\text { (LDS3) }\end{array}$ & $\begin{array}{l}\text { TGFB2 } \\
\text { (LDS4) }\end{array}$ & $\begin{array}{l}\text { TGFB3 } \\
\text { (LDS5) }\end{array}$ & Total \\
\hline Number of patients & $n=15$ & $\mathrm{n}=14$ & $n=3$ & $\mathrm{n}=7$ & $n=1$ & $\mathrm{n}=40$ \\
\hline Abnormal palate & $15(100.0)$ & $13(92.8)$ & $0(0.0)$ & $5(71.4)$ & $1(100.0)$ & $34(85.0)$ \\
\hline Retrognathic mandible & $14(93.3)$ & $13(92.8)$ & $2(66.7)$ & $4(57.1)$ & $0(0.0)$ & $33(82.5)$ \\
\hline Enamel defects & $7(46.7)$ & $10(71.4)$ & $2(66.7)$ & $3(42.8)$ & $0(0.0)$ & $22(55.0)$ \\
\hline Class II malocclusion & $8(53.3)$ & $9(64.2)$ & $2(66.7)$ & $3(42.8)$ & $0(0.0)$ & $22(55.0)$ \\
\hline Gingivitis & $9(60.0)$ & $9(64.2)$ & $1(33.3)$ & $0(0.0)$ & $1(100.0)$ & $20(50.0)$ \\
\hline Submucosal cleft or abnormal uvula & $6(40.0)$ & $9(64.3)$ & $0(0.0)$ & $0(0.0)$ & $0(0.0)$ & $15(37.5)$ \\
\hline TMJ abnormality & $6(40.0)$ & $5(35.7)$ & $1(33.3)$ & $1(14.3)$ & $1(100.0)$ & $14(35.0)$ \\
\hline Deep bite & $6(40.0)$ & $5(38.5)$ & $0(0.0)$ & $1(14.3)$ & $1(100.0)$ & $13(33.3)$ \\
\hline Dental crowding & $1(6.7)$ & $3(21.4)$ & $2(66.7)$ & $1(14.3)$ & $0(0.0)$ & $7(17.5)$ \\
\hline Delayed eruption & $0(0.0)$ & $4(28.5)$ & $0(0.0)$ & $0(0.0)$ & $0(0.0)$ & $4(10.0)$ \\
\hline
\end{tabular}

Frequencies of each phenotype are mentioned along with the percentage within the category in parenthesis. Frequencies higher than $50 \%$ are bolded.

LDS, Loeys-Dietz syndrome; TMJ, temporomandibular joint.

\section{Patients with LDS present with a wide spectrum of oro-dental malformations}

The oro-dental features found in patients with LDS are summarised in table 2 (see online supplementary table 1 for individual patient data). The most common features ( $>50 \%$ of the cohort) among the LDS cohort included the presence of a high arched and/or narrow palate, enamel defects and class II skeletal malocclusion. Less common features included the presence of a bifid or broad uvula or submucous cleft, deep bite, dental crowding and abnormal eruption pattern with a delay in the eruption of the permanent teeth.

Narrow or high-arched palate is the most common oro-dental feature seen in the LDS cohort and is noted in 34 patients (85.0\%). Among these, 23 patients (57.5\%) exhibited both narrow and high-vaulted palate, which is often mistaken for a cleft palate (figure 1A). We only found three patients $(7.5 \%)$ with an actual submucous cleft palate identified as a hard palate notch (instead of a posterior palatal spine), and no cleft lip or palate was noted in this cohort. A bifid uvula, which is considered as a minor form of a cleft palate, was present in 14 patients (35.0\%) (figure 1B).

Due to the combination of the narrow and high-arched palate, the limitation of arch space was responsible for dental crowding in seven patients (17.5\%) (figure 1C). Combined with crowding, due to the narrow palate, some individuals also had impacted upper canines or premolars. Crowding results in difficulty for some teeth to erupt and malalignment of the erupted teeth, worsening the dental malocclusion in these patients (figure 1D). Posterior dental crossbite was another form of dental malocclusion found in some patients either due to the narrow palate/ maxilla or due to deviation and asymmetry of one of the jaws (figure 1E). Delayed eruption of permanent teeth was noticed in four patients (10\%), in combination with delayed exfoliation of the deciduous teeth (figure 1F). Differences in the number of retrognathic patients and those with class II malocclusion were observed, however, some patients had done or were undergoing orthodontic treatment at the time of evaluation, and some patients were skeletally retrognathic with normal (class I) occlusion.

Mild degree of gingivitis, affecting more than one quadrant of the mouth, was noted in 20 patients $(50.0 \%)$, with increased frequency with age (online supplementary table 2). No abnormal mucosal findings were observed in this LDS cohort. None of the patients had clinically obvious salivary gland dysfunction or self-reported dry mouth. Despite several reports finding joint hyperlaxity in patients with LDS, we did not note laxity of the TMJ in any of the 40 patients. In contrast, 14 patients (35.0\%) had restricted mouth opening, either due to small oral orifice or TMJ abnormality. Interestingly, TMJ abnormalities were reported at a higher frequency in adults (online supplementary table 2). We did not notice any abnormalities of tooth shape in this cohort. Only one patient with LDS2 had congenitally missing teeth. Three out of four second premolars were congenitally missing (figure $1 \mathrm{G}$ ). We did not see any gender predilection in the frequency of these anomalies in our LDS cohort, most traits were distributed in a similar fashion across both genders (online supplementary table 2).

\section{Varying degrees of enamel defects are found in the LDS cohort}

Among the LDS cohort, 55.0\% had some form of enamel defect (table 2), ranging from minor discolouration to severe chipping and loss of enamel structure. We further classified the enamel defects in these subjects into four severity grades based on the type of structural defect, surface area of individual teeth affected and total number of teeth affected (table 3 and figure 2A). Individual patient data can be found in online supplementary table 1. We graded the unaffected family members in an analogous manner as controls. Fourteen of the patients with LDS (35.0\%) showed mild enamel defects which involved surface discolourations and white spot lesions affecting six or fewer teeth (grade 1), whereas 6 out of 26 unaffected family members (23.1\%) had grade 1 defects on our scale. Three patients (7.5\%) showed moderate defects, with fewer than 12 teeth affected, and the defect covering more than one-third of the tooth surface (grade 2). Three patients $(7.5 \%)$ had enamel defects covering almost two-thirds of the tooth surface and affecting $>12$ teeth in the dentition (grade 3). Two patients (5\%) had severe enamel defects with all teeth in the dentition being affected and defects covering the entire tooth surface even leading to loss of enamel following eruption (grade 4). Interestingly, 18 patients with LDS (45.0\%) did not exhibit clinically any form of enamel abnormality (grade 0 ) as opposed to most of unaffected family members (76.9\%). Overall, both primary and permanent dentitions were found to be affected in patients with LDS. No unaffected family members had any structural enamel defects (grade 2-4).

Consistent with the enamel defects, 19 of the patients with LDS (47.5\%) self-reported dental hypersensitivity to hot or cold stimuli, compelling them to alter their diet. The only patient with LDS5 in 
A

B

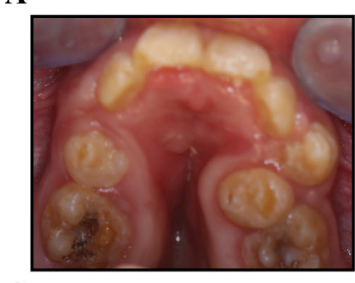

C

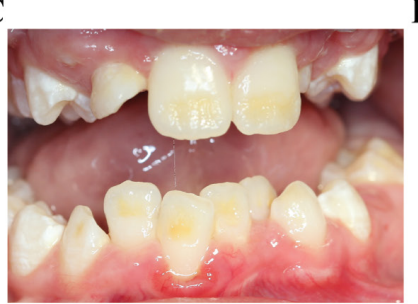

$\mathbf{F}$
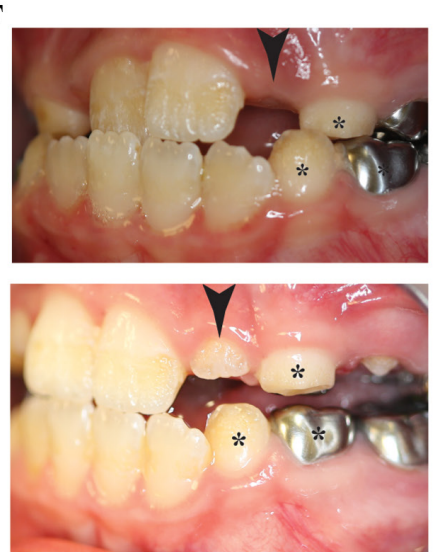

D
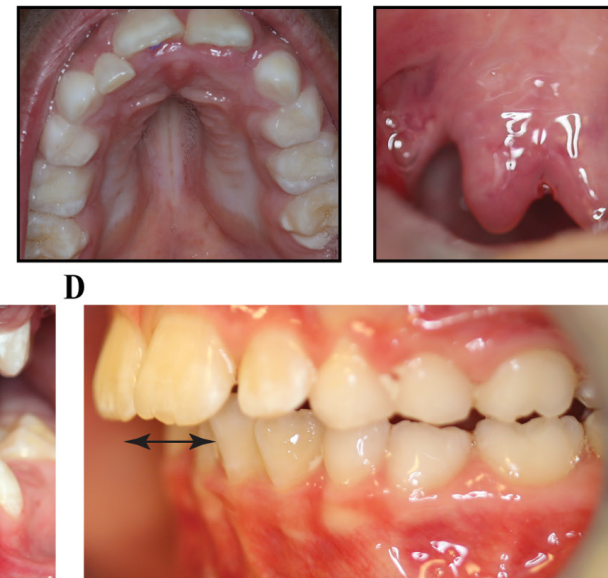

G

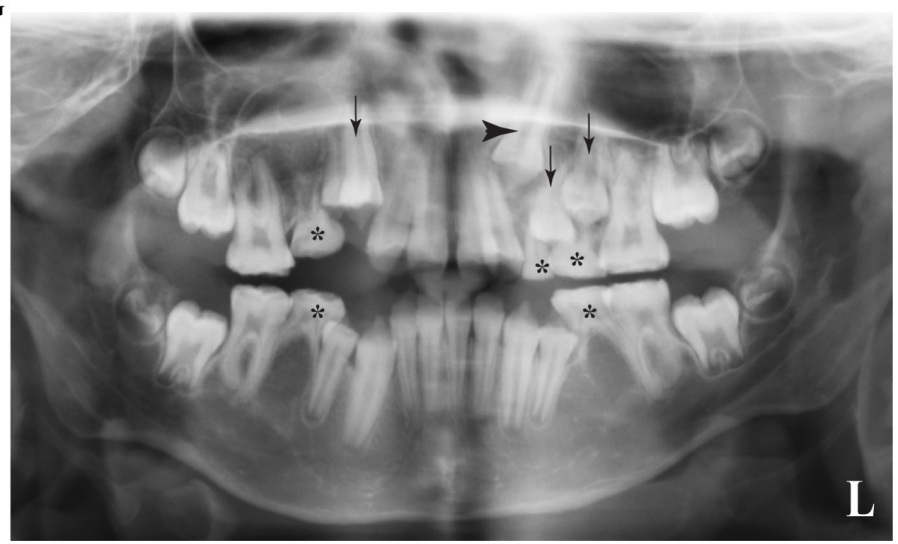

Figure 1 Common phenotypical characteristics in patients with Loeys-Dietz syndrome (LDS). (A) Narrow and high-arched palate in patient XIX with LDS2 and a high-arched palate in patient IIB with LDS1. The narrow palate in XIX resulted in severe crowding of teeth, malocclusion and posterior crossbite. (B) Bifid uvula in patient XVII with LDS2 and broad uvula in patient IIB. (C) Crowding of lower anterior teeth in patient XXV with LDS2. The crowding resulted from lack of space for permanent teeth mostly due to small (retrognathic) mandible. (D) Increased overjet of anterior teeth (double arrow) and class II dental malocclusion in patient VI with LDS1. (E) Bilateral posterior crossbite in patient IV. (F) Delayed dental eruption pattern in patient XVI with LDS2 with multiple retained deciduous teeth. The incisor was not visible in the oral cavity during patient's first visit at 10 years of age (top image, arrowhead) but was partially erupted in the visit after 1 year (bottom image, arrowhead). Also notable is the presence of several deciduous teeth at 11 years of age (bottom image, asterisk). (G) Panoramic X-ray of a patient 11 years of age with LDS2 having congenitally missing teeth \#4, \#20 and \#29, along with retained deciduous teeth (asterisk), unerupted permanent teeth (black arrows) and impacted tooth \#11 (black arrowhead).

the cohort also reported dental hypersensitivity, despite the absence of clinically evident enamel defects (grade 0). This may suggest that enamel defects may be more structurally subtle and not grossly apparent, or that dental hypersensitivity in these patients involves additional factors. Consistent with this latter hypothesis is the fact that, although enamel defects are found at comparable frequencies in all age groups (children, adolescents and adults), the frequency of patients suffering from hypersensitivity appears to increase with age (online supplementary table 2 ).

Even with the high rate of enamel defects in the LDS cohort, it was striking that very few had dental decay or caries. The loss of enamel and subsequent exposure of the underlying dentin would increase the risk for caries, yet patients with severe enamel defect and enamel loss did not show any obvious carious lesions at the time of examination.

\section{The severity and frequency of oro-dental manifestations is LDS subtype-dependent}

Patients with mutations in TGF- $\beta$ receptor 2 (LDS2) demonstrated the most severe oro-dental phenotypes among the cohort, including abnormal palate morphology, severe retrognathic

Table 3 Classification of dental enamel defects in Loeys-Dietz syndrome (LDS)

\begin{tabular}{|c|c|c|c|}
\hline Classification & Description & $\begin{array}{l}\text { LDS } \\
n=40\end{array}$ & $\begin{array}{l}\text { Unaffected } \\
n=26\end{array}$ \\
\hline Grade 0 & Normal enamel & $18(45.0)$ & $20(76.9)$ \\
\hline Grade 1 & Tooth discolouration: white, yellow or brown spots on smooth enamel surfaces & $14(35.0)$ & $6(23.1)$ \\
\hline Grade 2 & Localised $<2 / 3$ of structural defects: $<6$ teeth affected & $3(7.5)$ & $0(0.0)$ \\
\hline Grade 3 & Localised $\geq 2 / 3$ of structural defects: $<12$ teeth affected & $3(7.5)$ & $0(0.0)$ \\
\hline Grade 4 & Generalised structural defects: affect the whole dentition & $2(5.0)$ & $0(0.0)$ \\
\hline
\end{tabular}

\footnotetext{
Frequencies of each grade are mentioned along with the percentage within the category in parenthesis.
} 
A
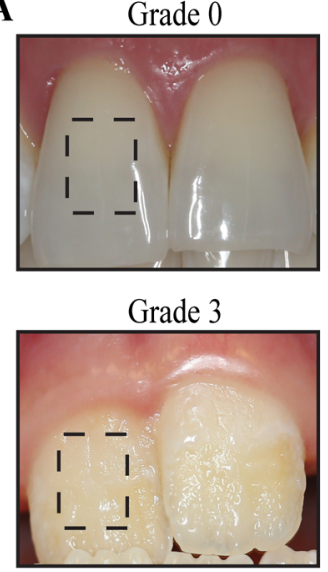

Grade 4

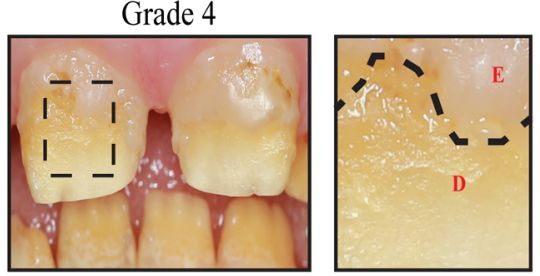

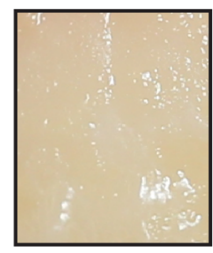

Grade 1

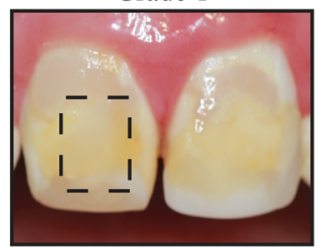

B
Grade 2
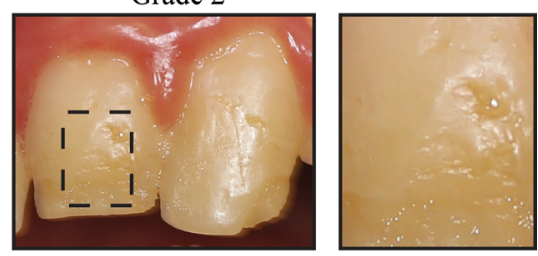

Enamel Defects

Grade 4

Grade 3

Grade 2

Grade 1

Grade 0

Figure 2 Grading of enamel defects in Loeys-Dietz syndrome (LDS). (A) Representative photos of various grades of enamel defects seen in patients with LDS, with the inset showing a magnified view of the boxed area of each tooth. Grade 0 shows normal incisors with no defects. Grade 1 shows the teeth with discolouration of enamel and white spots. Grade 2 shows mild enamel structural defects including pits and grooves. Grade 3 shows severe pitting of the enamel involving more than two-thirds of the surface. Severe structural defects leading to loss of enamel and dentin exposure was classified as grade 4 . The dotted line shows the extent of enamel loss and underlying dentin becoming visible. E, enamel, D, dentin. (B) Distribution of the different grades of enamel defects in patients with LDS. LDS2 has the most severe defects with two patients having grade 4 and three patients having grade 3 defects. LDS1 only had one patient with grade 2, while six had grade 1 defects. Grade 1 enamel defects were seen in two out of three LDS3 patients and three LDS4 patients.

mandible and class II malocclusion and bifid uvula or submucous cleft palate with the greatest frequency of anomalies (table 2). Moreover, as described in more detail below, patients with LDS2 exhibited the most severe enamel defects.

The second most common gene affected in patients with LDS is TGFBR 1 and our findings from these patients indicated that this subtype shared most clinical features with LDS2 but was not as severe as the latter. This group of patients did not have delayed eruption and their dental age complemented their chronological age.

Although the other three subtypes had lower prevalence, they shared most of the oro-dental features found in LDS1 and LDS2 as seen in table 2. Nevertheless, most of the examined manifestations were less frequent when compared with LDS1 or LDS2.

\section{The most severe enamel defects are seen in LDS2 with incomplete penetrance and variable expression}

The distribution of patients with LDS based on the grading of their enamel defect is depicted for each LDS subtype in figure 2B. Patients with LDS2 exhibited the highest frequency and severity of enamel defects; 10 out of 14 patients had defective enamel (71.4\%), with 3 of them presenting with severe defects (grade 3 ) and two suffering from enamel loss affecting the whole dentition (grade 4) (figures 2B and 3A). However, four patients (28.6\%) with LDS2 presented with no clinically apparent enamel defects, which suggests an incomplete penetrance of enamel defects in LDS. It was also noted that both mandibular and maxillary incisors were commonly affected in patients with LDS2, while in the other LDS subtypes the maxillary incisors were more often affected than the mandibular incisors.
Given the range of severity in the LDS2 group, we examined the correlation between the position of the mutation in the TGFBR2 gene and the severity of the enamel phenotype. In the LDS2 group, we did not see any correlation between the position of the mutations in the protein kinase domain of TGFR- 2 and the severity of enamel defects (figure 3B). Five patients with the same $\mathrm{R} 528 \mathrm{H}$ variant presented with varying degrees of enamel defects (figure $3 \mathrm{~A}$ and $\mathrm{C}$ ), and the same variability was observed in family members who had the same V419E variant (figure 3D).

The second most severe enamel phenotype was found in LDS1, although there is also a large range of variability. Seven patients with LDS1 (46.7\%) had mild-to-moderate enamel defects, ranging from grade 1 to 2 , based on our grading scale (figure $2 \mathrm{~B}$ and online supplementary figure $1 \mathrm{~A}$ ). Similar to what was observed for LDS2, there was no correlation between the position of the variants in TGFR-1 and severity of enamel defects (online supplementary figure $1 \mathrm{~B}$ and $\mathrm{C}$ ).

For the three other LDS subtypes (LDS3, LDS4 and LDS5), only mild enamel defects (grade 1) or normal enamel were observed (figure $2 \mathrm{~B}$ and online supplementary figure 2); two patients with LDS3 (66.7\%) and three patients with LDS4 $(42.8 \%)$ presented with tooth discolouration (grade 1$)$. The only patient with LDS5 in this cohort did not exhibit any clinically discernible enamel defects (figure $2 \mathrm{~B}$ and online supplementary figure 2).

\section{DISCUSSION}

In this study, we thoroughly characterised the oro-dental malformations in patients with LDS. We reported for the first time detailed common and distinguishing characteristics of different 
$\mathbf{A}$
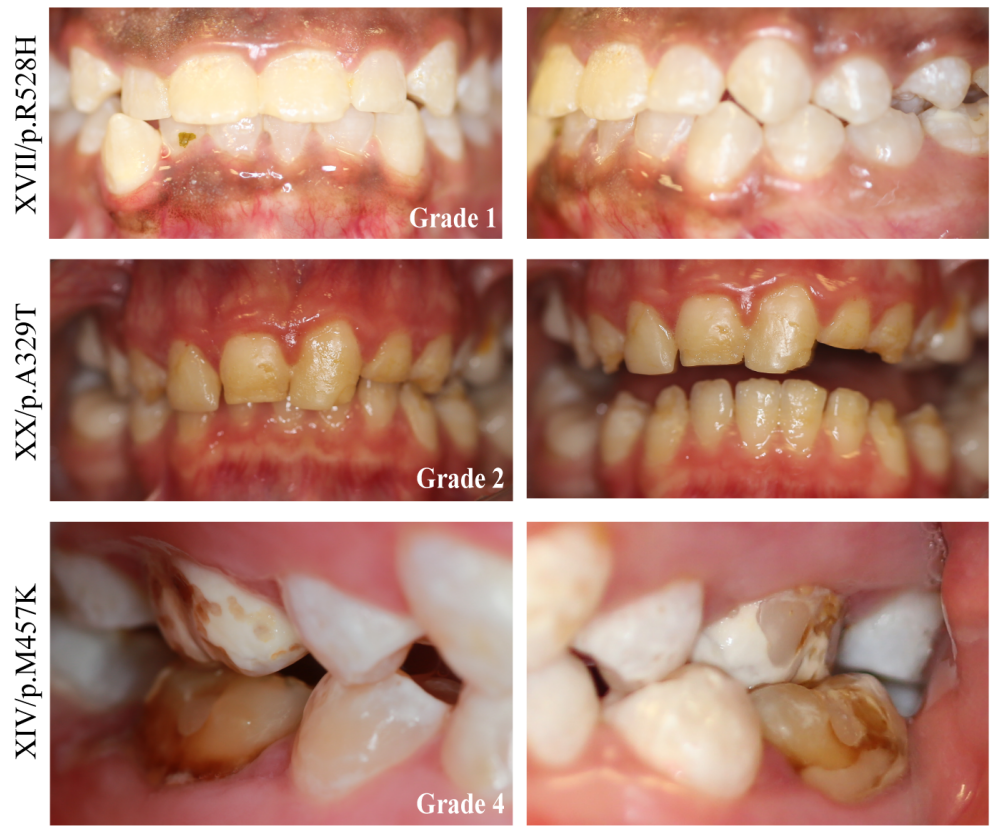

B

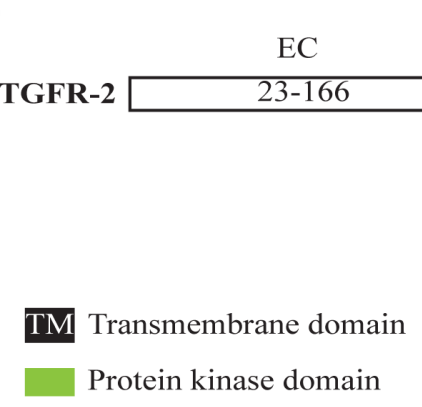

C

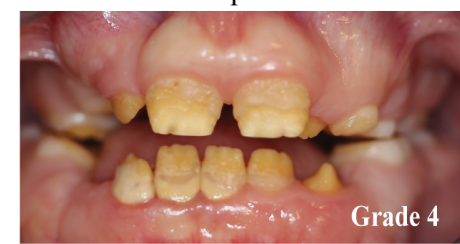

$\mathrm{XXV} / \mathrm{p} \cdot \mathrm{R} 528 \mathrm{H}$

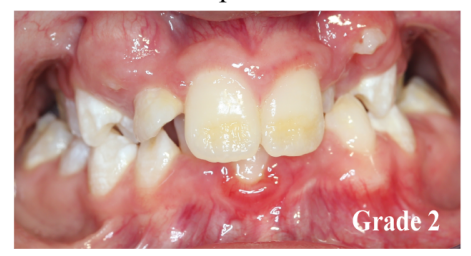

1

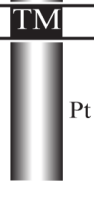

IC

Figure 3 Mutations in transforming growth factor-beta (TGF- $\beta$ ) receptor type 2 (TGFBR2) lead to varying degrees of enamel defects. (A) Varying degrees of severity of enamel defects seen in LDS2 patients with patient XIV showing severe loss of enamel (grade 4), patient XX showing generalised discolouration of both upper and lower teeth (grade 2) and patient XVII only exhibiting mild discolouration and localised white spot lesions (grade 1). (B) Graphic representation of the TGF- $\beta$ receptor 2 protein (TGFR-2) showing the distribution of pathogenic variants in the LDS2 patients in this study. All LDS-causing mutations reported so far in TGFBR2 are in the region of the gene that encodes the intracellular protein kinase domain. We also mapped the severity of enamel defects to each variant and did not find any correlation between defect severity and variant position. EC, extracellular domain, IC, intracellular domain. (C) LDS2 patients with same pathogenic variant (p.R528H) presenting varying severity of enamel defects, once again showing the variability in LDS phenotype. (D) Patients in the same family with p.V419E mutation showing different grades of enamel defects with father (top image) having grade 1 defects and daughter (bottom image) having no evident enamel defects. LDS, Loeys-Dietz syndrome. 
LDS subtypes. Overall, patients with LDS2 exhibited the greatest frequency and severity of oro-dental anomalies, while LDS1 patients presented the second most severe phenotype in the cohort. The presence of a bifid uvula and/or submucous cleft palate were only observed in individuals with LDS1 and LDS2. The eruption pattern of teeth was only affected in patients with LDS2, with retention of deciduous teeth and consequent delay in the eruption of permanent teeth. These findings demonstrate that alterations in the TGF- $\beta$ signalling pathway in the context of oro-dental development, particularly mutations in the transmembrane receptor subunits (TGFR-1 and TGFR-2), and even more so for the receptor subunit that is directly involved in the interaction with the ligand (TGFR-2), are more deleterious than mutations affecting the ligands (TGF- $\beta 2$ and TGF- $\beta 3$ ) or signal transducers (SMAD3). In addition to this variability related to the position of the mutation along the various components of the signalling pathway, strong clinical variability was also found within each LDS subtypes, specifically for the enamel defects. Even within the group of patients with LDS2 where the most severe anomalies were observed, some patients did not exhibit any obvious enamel defects. Moreover, this clinical variability did not correlate with the position of the mutation in the protein kinase domain, and the same mutation can lead to a large range of anomalies. These findings suggest that the expression of orodental anomalies in LDS may be influenced by modifier genes or environmental factors.

The TGF- $\beta$ superfamily is known to play critical roles in mammalian development. Defects in TGF- $\beta$ signal transduction have been shown to be responsible for several developmental disorders and human diseases, ${ }^{29}{ }^{30}$ and TGF- $\beta$ signalling is an important regulator during craniofacial development. ${ }^{31}$ In mice, Tgfbr 1 and Tgfbr2 are expressed in the developing craniofacial region, and deletion of either receptor in neural crest cells (using Wnt1-cre mice) results in an array of craniofacial deformities including cleft palate and mandibular hypoplasia, clearly indicating the functional significance of TGF- $\beta$ signalling in regulating craniofacial development. ${ }^{24} 3233$ None of the patients in our cohort exhibited a complete cleft palate. However, three patients were confirmed to have submucosal clefts and nearly one-third presented with a bifid uvula, which can be considered as a mild form of clefting. Most patients also presented with a considerably high arching of the palate, which is occasionally misreported by non-experts as cleft palate.

As this study was based on clinical examinations and intraoral photos, the dental defects described here are mostly focused on the appearance of the tooth surface and therefore on dental enamel. Ultrastructural and biomechanical analyses will be essential to further characterise the type of enamel defects in patients with LDS. Enamel is the hardest tissue in the body (96\% mineral content) and is produced by ameloblasts through a process called amelogenesis. Amelogenesis happens in two stages: a secretion stage, during which enamel matrix proteins are deposited simultaneously with the initiation of hydroxyapatite crystallite formation, and a maturation stage, during which enamel matrix proteins are degraded to leave space for the full growth of hydroxyapatite crystals. ${ }^{23} 34$ Disruption of any of these processes may cause enamel defects. ${ }^{35}$ The importance of TGF- $\beta$ signalling in enamel development has been suggested by studies in cells, even though these studies used TGF- $\beta 1$ ligand, the only ligand that has not been involved in LDS, as a paradigm for the activation of TGF- $\beta$ signalling. ${ }^{36}{ }^{37}$ In mice, the deletion of the Tgfbr2 gene in ameloblasts results in defects in enamel mineralisation and maturation, ${ }^{25}$ which supports the importance of TGF- $\beta$ signalling in enamel development in an in vivo setting.
However, complete absence of the receptor in ameloblasts is not an ideal model for LDS as an autosomal dominant or heterozygous mutation in Tgfbr 2 may affect the signalling pathway in a totally different way. Moreover, mutations in patients with LDS may affect the ameloblasts and other cells in the enamel organ, as well as the dental mesenchyme that interacts closely with the enamel organ during tooth development. Therefore, the use of an LDS mouse model ${ }^{38}$ will be essential to investigate the molecular and cellular events leading to enamel defects in this syndrome.

The observations presented in this study do not allow us to make any conclusion on the consequences of LDS-causing mutations on dentin formation. In our cohort, only one patient with LDS1 exhibited a phenotype similar to dentinogenesis imperfecta resulting in the pathognomonic severe grey tooth discolouration. The involvement of TGF- $\beta$ signalling in dentin development is supported by numerous mouse studies. ${ }^{263940}$ Dentin is produced by odontoblasts that are part of the dental mesenchyme and are derived from neural crest cells. TGF- $\beta$ ligands and receptors are known to be expressed by odontoblasts, ${ }^{204142}$ where they act in an autocrine manner to stimulate the secretion of predentin and dentin. In human teeth, strong staining for both TGF- $\beta$ receptors 1 and 2 has been reported in the odontoblasts of healthy teeth. ${ }^{41}$ These studies suggest that patients with LDS may exhibit dentin defects in addition to the enamel anomalies described here. Therefore, ultrastructural analysis of teeth from patients with LDS will be essential to further investigate the effects of LDS-causing mutations on dentin formation.

In our report, we present an in-depth characterisation of the oro-dental features of LDS, and we demonstrate the phenotypic heterogeneity and segregation among the different LDS subtypes, with LDS2 having the most severe oro-dental phenotype. Our findings in LDS show a much higher prevalence of certain traits than in the general population. Enamel defects in the general population show a large range of variation depending on the racial, ethnic, nutritional or socioeconomic status. A recent study showed that $27 \%$ of the 698 children examined in the Iowa Fluoride Study had at least one tooth with enamel opacities (grade 1 on our scale) and, $<1 \%$ children had up to four teeth with defects, ${ }^{43}$ whereas $35 \%$ of patients with LDS had grade 1 enamel defects. Similarly, for malocclusion in the general population, Caucasians show the highest prevalence of class II malocclusion in the permanent dentition (23\%), ${ }^{44}$ which is significantly lower than our finding in LDS (55\%). About 25\%-30\% of the adult population report dentin hypersensitivity. ${ }^{45}$ We find that $47.5 \%$ of patient with LDS have hypersensitivity. Thus, patients affected with LDS have greater severity and have much higher frequency of some of the anomalies found in the general population.

The clinical management of patients with LDS has been focused on the life-threatening cardiovascular manifestations. Based on the severity of oro-dental anomalies in the LDS cohort in our study, we recommend more thorough dental evaluations and comprehensive treatment planning. These patients should be evaluated by clinical teams consisting of various specialists including dentists, orthodontists and oral and maxillofacial surgeons, preferably in a multidisciplinary setting and in regular communication with the primary paediatrician or cardiologist. Early visits to dentists and orthodontist are also highly recommended. Dentinal hypersensitivity should be addressed and could be temporarily relieved with a topical application of fluoride varnish or desensitiser. Patients in our LDS cohort who had desensitiser application, felt relief from hypersensitivity up to 3 months. Patients having severe enamel defects and enamel loss can have prosthetic crowns placed to cap the teeth and prevent 
further damage. Primary teeth can have stainless steel crowns for posterior teeth or silicone crowns for anterior teeth so they can maintain space until permanent teeth erupt. A multidisciplinary cleft and craniofacial team can provide comprehensive oversight of the oro-dental findings.

Future studies on the ultrastructure and biomechanical properties of dental tissues from patients with LDS, as well as phenotypic and molecular analyses of animal models mimicking LDS-causing mutations will help improve our understanding of the molecular and cellular mechanisms leading to oro-dental anomalies in LDS.

\section{Twitter Priyam Jani @priyamjan}

Acknowledgements The authors would like to thank the personnel of the NIDCR Dental Clinic who was involved in the collection of the data and the patients who participated in the study.

Contributors PJ, RM and JSL performed the clinical evaluation of patients. PO recruited and consented the patients. PJ, QN, KA, CK, DL and OD performed the analysis and interpretation of data. JSL and PAF-G obtained IRB approval and secured research funding, identified and recruited patients with LDS. PJ, QN, OD and JSL wrote the manuscript. All authors reviewed the manuscript critically for important intellectual content and approved the version to be published.

Funding This research was funded by the Intramural Research Program of the National Institute of Dental and Craniofacial Research (PI: JSL, DDS, MD, FACS, ZIA DE000746 04 and ZID DE000728 10) and National Institute of Allery and Infectious Diseases (PI: PAF-G, MD, PhD, ZIA AI001203 04).

\section{Competing interests None declared.}

\section{Patient consent for publication Not required.}

Ethics approval The main study and the collaborated study protocols were approved by the institutional review boards at their respective institute (ClinicalTrials. gov numbers, NCT02639312 for the Natural History of Craniofacial Anomalies and Developmental Growth Variants study and NCT02504853 for the Natural History and Genetics of Food Allergy and Related Conditions study). A signed informed consent was obtained from all the participating patients and/or their guardians.

Provenance and peer review Not commissioned; externally peer reviewed.

Data availability statement Data are available on reasonable request. All data relevant to the study are included in the article or uploaded as supplementary information. Deidentified participant data will be shared on request by contacting either the primary or the corresponding author.

Open access This is an open access article distributed in accordance with the Creative Commons Attribution Non Commercial (CC BY-NC 4.0) license, which permits others to distribute, remix, adapt, build upon this work non-commercially, and license their derivative works on different terms, provided the original work is properly cited, appropriate credit is given, any changes made indicated, and the use is non-commercial. See: http://creativecommons.org/licenses/by-nc/4.0/.

\section{ORCID iDs}

Priyam Jani http://orcid.org/0000-0001-7768-7865

Quynh C Nguyen http://orcid.org/0000-0003-2084-4473

Konstantinia Almpani http://orcid.org/0000-0001-7558-6796

Cyrus Keyvanfar http://orcid.org/0000-0001-8681-6577

Rashmi Mishra http://orcid.org/0000-0002-3696-750X

Denise Liberton http://orcid.org/0000-0002-2885-8864

Pamela Orzechowski http://orcid.org/0000-0003-4973-1413

Pamela A Frischmeyer-Guerrerio http://orcid.org/0000-0003-2259-5546

Olivier Duverger http://orcid.org/0000-0003-3200-1019

Janice S Lee http://orcid.org/0000-0001-5164-5958

\section{REFERENCES}

1 National Institutes of Health RDD. Available: https://rarediseases.info.nih.gov/diseases/ diseases-by-category/23/mouth-diseases

2 Bloch-Zupan A, Sedano HO, Scully C. 1 - Odontogenesis, anomalies and genetics. In: Bloch-Zupan A, Sedano HO, Scully C, eds. Dento/Oro/Craniofacial anomalies and genetics. London: Elsevier, 2012: 1-8.

3 Gorlin RJ, Cohen Jr MM, Hennekam RC. Syndromes of the head and neck. Oxford university press, 2001.

4 Loeys BL, Chen J, Neptune ER, Judge DP, Podowski M, Holm T, Meyers J, Leitch CC, Katsanis N, Sharifi N, Xu FL, Myers LA, Spevak PJ, Cameron DE, De Backer J, Hellemans J, Chen Y, Davis EC, Webb CL, Kress W, Coucke P, Rifkin DB, De Paepe AM, Dietz HC. A syndrome of altered cardiovascular, craniofacial, neurocognitive and skeletal development caused by mutations in TGFBR1 or TGFBR2. Nat Genet 2005;37:275-81.

5 Loeys BL, Schwarze U, Holm T, Callewaert BL, Thomas GH, Pannu H, De Backer JF, Oswald GL, Symoens S, Manouvrier S, Roberts AE, Faravelli F, Greco MA, Pyeritz RE, Milewicz DM, Coucke PJ, Cameron DE, Braverman AC, Byers PH, De Paepe AM, Dietz HC. Aneurysm syndromes caused by mutations in the TGF-beta receptor. N Engl I Med 2006;355:788-98

6 van de Laar IMBH, Oldenburg RA, Pals G, Roos-Hesselink JW, de Graaf BM, Verhagen JMA, Hoedemaekers YM, Willemsen R, Severijnen L-A, Venselaar $H$, Vriend $G$, Pattynama PM, Collée M, Majoor-Krakauer D, Poldermans D, Frohn-Mulder IME, Micha D, Timmermans J, Hilhorst-Hofstee Y, Bierma-Zeinstra SM, Willems PJ, Kros JM, Oei EHG, Oostra BA, Wessels MW, Bertoli-Avella AM. Mutations in Smad3 cause a syndromic form of aortic aneurysms and dissections with early-onset osteoarthritis. Nat Genet 2011;43:121-6.

7 Bertoli-Avella AM, Gillis E, Morisaki H, Verhagen JMA, de Graaf BM, van de Beek G, Gallo E, Kruithof BPT, Venselaar H, Myers LA, Laga S, Doyle AJ, Oswald G, van Cappellen GWA, Yamanaka I, van der Helm RM, Beverloo B, de Klein A, Pardo L, Lammens M, Evers C, Devriendt K, Dumoulein M, Timmermans J, Bruggenwirth HT, Verheijen F, Rodrigus I, Baynam G, Kempers M, Saenen J, Van Craenenbroeck EM, Minatoya K, Matsukawa R, Tsukube T, Kubo N, Hofstra R, Goumans MJ, Bekkers JA, Roos-Hesselink JW, van de Laar IMBH, Dietz HC, Van Laer L, Morisaki T, Wessels MW, Loeys BL. Mutations in a TGF- $\beta$ ligand, TGFB3, cause syndromic aortic aneurysms and dissections. J Am Coll Cardiol 2015;65:1324-36.

8 Boileau C, Guo D-C, Hanna N, Regalado ES, Detaint D, Gong L, Varret M, Prakash SK, Li AH, d'Indy H, Braverman AC, Grandchamp B, Kwartler CS, Gouya L, Santos-Cortez RLP, Abifadel M, Leal SM, Muti C, Shendure J, Gross M-S, Rieder MJ, Vahanian A, Nickerson DA, Michel JB, Jondeau G, Milewicz DM, National Heart, Lung, and Blood Institute (NHLBI) Go Exome Sequencing Project. Tgfb2 mutations cause familial thoracic aortic aneurysms and dissections associated with mild systemic features of Marfan syndrome. Nat Genet 2012;44:916-21.

9 Lindsay ME, Schepers D, Bolar NA, Doyle JJ, Gallo E, Fert-Bober J, Kempers MJE, Fishman EK, Chen Y, Myers L, Bjeda D, Oswald G, Elias AF, Levy HP, Anderlid B-M, Yang MH, Bongers EMHF, Timmermans J, Braverman AC, Canham N, Mortier GR, Brunner HG, Byers PH, Van Eyk J, Van Laer L, Dietz HC, Loeys BL. Loss-Of-Function mutations in TGFB2 cause a syndromic presentation of thoracic aortic aneurysm. Nat Genet 2012;44:922-7.

10 Rienhoff HY, Yeo C-Y, Morissette R, Khrebtukova I, Melnick J, Luo S, Leng N, Kim Y-J, Schroth G, Westwick J, Vogel H, McDonnell N, Hall JG, Whitman M. A mutation in TGFB 3 associated with a syndrome of low muscle mass, growth retardation, distal arthrogryposis and clinical features overlapping with marfan and loeys-dietz syndrome. Am J Med Genet A 2013;161:2040-6.

11 Micha D, Guo D-C, Hilhorst-Hofstee Y, van Kooten F, Atmaja D, Overwater E, Cayami $F K$, Regalado ES, van Uffelen $R$, Venselaar $H$, Faradz SMH, Vriend G, Weiss MM, Sistermans EA, Maugeri A, Milewicz DM, Pals G, van Dijk FS. SMAD2 Mutations Are Associated with Arterial Aneurysms and Dissections. Hum Mutat 2015;36:1145-9.

12 Kinoshita A, Saito T, Tomita H, Makita Y, Yoshida K, Ghadami M, Yamada K, Kondo S, Ikegawa S, Nishimura G, Fukushima Y, Nakagomi T, Saito H, Sugimoto T, Kamegaya M, Hisa K, Murray JC, Taniguchi N, Niikawa N, Yoshiura K. Domain-Specific mutations in TGFB1 result in Camurati-Engelmann disease. Nat Genet 2000;26:19-20.

13 Kotlarz D, Marquardt B, Barøy T, Lee WS, Konnikova L, Hollizeck S, Magg T, Lehle AS, Walz C, Borggraefe I, Hauck F, Bufler P, Conca R, Wall SM, Schumacher EM, Misceo $D$, Frengen E, Bentsen BS, Uhlig HH, Hopfner K-P, Muise AM, Snapper SB, Strømme $P$, Klein C. Human TGF- $\beta 1$ deficiency causes severe inflammatory bowel disease and encephalopathy. Nat Genet 2018;50:344-8.

14 Bradley TJ, Bowdin SC, Morel CFJ, Pyeritz RE. The expanding clinical spectrum of Extracardiovascular and cardiovascular manifestations of heritable thoracic aortic aneurysm and dissection. Can J Cardiol 2016;32:86-99.

15 MacCarrick G, Black JH, Bowdin S, El-Hamamsy I, Frischmeyer-Guerrerio PA, Guerrerio AL, Sponseller PD, Loeys B, Dietz HC. Loeys-Dietz syndrome: a primer for diagnosis and management. Genet Med 2014;16:576-87.

16 Williams JA, Loeys BL, Nwakanma LU, Dietz HC, Spevak PJ, Patel ND, François K, DeBacker J, Gott VL, Vricella LA, Cameron DE. Early surgical experience with LoeysDietz: a new syndrome of aggressive thoracic aortic aneurysm disease. Ann Thorac Surg 2007;83:S757-63.

17 Meester JAN, Verstraeten A, Schepers D, Alaerts M, Van Laer L, Loeys BL. Differences in manifestations of Marfan syndrome, Ehlers-Danlos syndrome, and Loeys-Dietz syndrome. Ann Cardiothorac Surg 2017;6:582-94.

18 van de Laar IMBH, van der Linde D, Oei EHG, Bos PK, Bessems JH, Bierma-Zeinstra SM, van Meer BL, Pals G, Oldenburg RA, Bekkers JA, Moelker A, de Graaf BM, Matyas G, Frohn-Mulder IME, Timmermans J, Hilhorst-Hofstee $Y_{\text {, Cobben JM, Bruggenwirth }}$ HT, van Laer L, Loeys B, De Backer J, Coucke PJ, Dietz HC, Willems PJ, Oostra BA, De Paepe A, Roos-Hesselink JW, Bertoli-Avella AM, Wessels MW. Phenotypic spectrum of the SMAD3-related aneurysms-osteoarthritis syndrome. J Med Genet 2012;49:47-57.

19 Van Hemelrijk C, Renard M, Loeys B. The Loeys-Dietz syndrome: an update for the clinician. Curr Opin Cardiol 2010;25:546-51.

20 Cassidy N, Fahey M, Prime SS, Smith AJ. Comparative analysis of transforming growth factor-beta isoforms 1-3 in human and rabbit dentine matrices. Arch Oral Biol 1997:42:219-23 
21 D'Souza RN, Cavender A, Dickinson D, Roberts A, Letterio J. TGF-Beta1 is essential for the homeostasis of the dentin-pulp complex. Eur J Oral Sci 1998;106(Suppl 1):185-91.

22 Wurdak H, Ittner LM, Lang KS, Leveen P, Suter U, Fischer JA, Karlsson S, Born W, Sommer L. Inactivation of TGFbeta signaling in neural crest stem cells leads to multiple defects reminiscent of DiGeorge syndrome. Genes Dev 2005;19:530-5.

23 Bartlett JD, Ganss B, Goldberg M, Moradian-Oldak J, Paine ML, Snead ML, Wen X, White SN, Zhou YL. 3. Protein-protein interactions of the developing enamel matrix. Curr Top Dev Biol 2006;74:57-115.

24 Dudas M, Kim J, Li W-Y, Nagy A, Larsson J, Karlsson S, Chai Y, Kaartinen V. Epithelial and ectomesenchymal role of the type I TGF-beta receptor ALK5 during facial morphogenesis and palatal fusion. Dev Biol 2006;296:298-314.

25 Cho A, Haruyama N, Hall B, Danton MJS, Zhang L, Arany P, Mooney DJ, Harichane Y, Goldberg M, Gibson CW, Kulkarni AB. TGF-ß regulates enamel mineralization and maturation through KLK4 expression. PLoS One 2013;8:e82267.

26 Wang Y, Cox MK, Coricor G, MacDougall M, Serra R. Inactivation of Tgfbr2 in Osterix-Cre expressing dental mesenchyme disrupts molar root formation. Dev Biol 2013;382:27-37.

27 Nguyen QC, Duverger O, Mishra R, Mitnik GL, Jani P, Frischmeyer-Guerrerio PA, Lee JS. Oral health-related quality of life in Loeys-Dietz syndrome, a rare connective tissue disorder: an observational cohort study. Orphanet J Rare Dis 2019;14:291.

28 Aine L, Mäki M, Collin P, Keyriläinen O. Dental enamel defects in celiac disease. J Oral Pathol Med 1990;19:241-5.

29 Blobe GC, Schiemann WP, Lodish HF. Role of transforming growth factor beta in human disease. N Engl J Med 2000;342:1350-8.

30 Massagué J, Blain SW, Lo RS. TGFbeta signaling in growth control, cancer, and heritable disorders. Cell 2000;103:295-309.

31 Chai Y, Ito Y, Han J. TGF-beta signaling and its functional significance in regulating the fate of cranial neural crest cells. Crit Rev Oral Biol Med 2003;14:78-88.

32 Ito Y, Yeo JY, Chytil A, Han J, Bringas P, Nakajima A, Shuler CF, Moses HL, Chai Y. Conditional inactivation of Tgfbr2 in cranial neural crest causes cleft palate and calvaria defects. Development 2003;130:5269-80.

$33 \mathrm{Xu} \mathrm{X,} \mathrm{Han} \mathrm{J,} \mathrm{Ito} \mathrm{Y,} \mathrm{Bringas} \mathrm{P,} \mathrm{Urata} \mathrm{MM,} \mathrm{Chai} \mathrm{Y.} \mathrm{Cell} \mathrm{autonomous} \mathrm{requirement} \mathrm{for}$ Tgfbr2 in the disappearance of medial edge epithelium during palatal fusion. Dev Biol 2006:297:238-48
34 Goldberg M, Septier D. Phospholipids in amelogenesis and dentinogenesis. Crit Rev Oral Biol Med 2002;13:276-90.

35 Hu JC-C, Chun Y-HP, Al Hazzazzi T, Simmer JP. Enamel formation and amelogenesis imperfecta. Cells Tissues Organs 2007;186:78-85.

36 Gao Y, Li D, Han T, Sun Y, Zhang J. TGF-Beta1 and TGFBR1 are expressed in ameloblasts and promote MMP20 expression. Anat Rec 2009;292:885-90.

37 Kobayashi-Kinoshita S, Yamakoshi Y, Onuma K, Yamamoto R, Asada Y. TGF- $\beta$ autocrine signalling and enamel matrix components. Sci Rep 2016;6:33644.

38 Gallo EM, Loch DC, Habashi JP, Calderon JF, Chen Y, Bedja D, van Erp C, Gerber EE, Parker SJ, Sauls K, Judge DP, Cooke SK, Lindsay ME, Rouf R, Myers L, ap Rhys CM, Kent KC, Norris RA, Huso DL, Dietz HC. Angiotensin II-dependent TGF- $\beta$ signaling contributes to Loeys-Dietz syndrome vascular pathogenesis. J Clin Invest 2014;124:448-60.

39 Oka S, Oka K, Xu X, Sasaki T, Bringas P, Chai Y. Cell autonomous requirement for TGFbeta signaling during odontoblast differentiation and dentin matrix formation. Mech Dev 2007;124:409-15.

40 Ahn YH, Kim TH, Choi H, Bae CH, Yang YM, Baek JA, Lee JC, Cho ES. Disruption of Tgfbr2 in odontoblasts leads to aberrant pulp calcification. J Dent Res 2015;94:828-35.

41 Sloan AJ, Perry H, Matthews JB, Smith AJ. Transforming growth factor-beta isoform expression in mature human healthy and carious molar teeth. Histochem $\mathrm{J}$ 2000;32:247-52.

42 Sloan AJ, Matthews JB, Smith AJ. Tgf-Beta receptor expression in human odontoblasts and pulpal cells. Histochem J 1999;31:565-9.

43 Slayton RL, Warren JJ, Kanellis MJ, Levy SM, Islam M. Prevalence of enamel hypoplasia and isolated opacities in the primary dentition. Pediatr Dent 2001;23:32-6.

44 Alhammadi MS, Halboub E, Fayed MS, Labib A, El-Saaidi C. Global distribution of malocclusion traits: a systematic review. Dental Press J Orthod 2018;23:40.e1-10.

45 Cunha-Cruz J, Wataha JC, Heaton LJ, Rothen M, Sobieraj M, Scott J, Berg J, Northwest Practice-based Research Collaborative in Evidence-based DENTistry. The prevalence of dentin hypersensitivity in general dental practices in the northwest United States. J Am Dent Assoc 2013;144:288-96. 